\title{
Ice crystal $c$-axis orientation and mean grain size measurements from the Dome Summit South ice core, Law Dome, East Antarctica
}

\author{
Adam Treverrow $^{1}$, Li Jun ${ }^{2}$, and Tim H. Jacka ${ }^{1}$ \\ ${ }^{1}$ Antarctic Climate and Ecosystems Cooperative Research Centre, University of Tasmania, Hobart \\ 7004, Australia \\ ${ }^{2}$ SGT Inc., NASA Goddard Space Flight Center, Greenbelt, MD, USA \\ Correspondence to: Adam Treverrow (adam.treverrow@utas.edu.au)
}

Received: 21 December 2015 - Published in Earth Syst. Sci. Data Discuss.: 19 January 2016

Revised: 11 May 2016 - Accepted: 16 May 2016 - Published: 7 June 2016

\begin{abstract}
We present measurements of crystal $c$-axis orientations and mean grain area from the Dome Summit South (DSS) ice core drilled on Law Dome, East Antarctica. All measurements were made on location at the borehole site during drilling operations. The data are from 185 individual thin sections obtained between a depth of $117 \mathrm{~m}$ below the surface and the bottom of the DSS core at a depth of $1196 \mathrm{~m}$. The median number of $c$ axis orientations recorded in each thin section was 100, with values ranging from 5 through to 111 orientations. The data from all 185 thin sections are provided in a single comma-separated value (csv) formatted file which contains the $c$-axis orientations in polar coordinates, depth information for each core section from which the data were obtained, the mean grain area calculated for each thin section and other data related to the drilling site. The data set is also available as a MATLAB ${ }^{\mathrm{TM}}$ structure array. Additionally, the $c$-axis orientation data from each of the 185 thin sections are summarized graphically in figures containing a Schmidt diagram, histogram of $c$-axis colatitudes and rose plot of $c$-axis azimuths. All these data are referenced by doi:10.4225/15/5669050CC1B3B and are available free of charge at https://data.antarctica.gov.au.
\end{abstract}

1

The greatest source of uncertainty in forecasts of sea level rise during the 21 st century is the contribution from the Antarctic and Greenland ice sheets (e.g. Willis and Church, 2012; Gregory et al., 2013). The poor constraints on predictions of grounded ice discharge are related to the currently inadequate description of ice dynamic processes and boundary conditions in numerical models used to simulate ice sheet evolution (e.g. Alley and Joughin, 2012; Gregory et al., 2013; Vaughan et al., 2013; Carson et al., 2014). One of the key components of all numerical ice sheet models is the relationship which governs ice flow rates as a function of temperature and the stresses driving the deformation. The primary consideration in the development of a numerical flow relation for ice sheet modelling is to provide a realistic description of ice rheology that does not significantly decrease the computational efficiency of the model.

Typically, ice is modelled as a very slow flowing, nonlinear viscoplastic fluid where the effective viscosity is highly temperature dependent, varying by $\sim 3$ orders of magnitude over the in situ temperature range. Despite being modelled as a high-viscosity fluid, the polar ice sheets are massive polycrystalline aggregates of solid ice, where the largest linear dimension of individual grains is in the order of several millimetres to centimetres (e.g. Faria et al., 2014a; $\mathrm{Ng}$ and Jacka, 2014). Furthermore, ice flow rates are significantly influenced by the microstructural evolution which occurs during deformation (e.g. Budd and Jacka, 1989; Cuffey and Paterson, 2010).

Under terrestrial conditions ice exists in the hexagonal Ih phase and individual crystals possess a high level of plastic anisotropy because their dominant mode of deformation is 
slip on crystallographic basal planes (e.g. Duval et al., 1983; Schulson and Duval, 2009; Cuffey and Paterson, 2010). Within a polycrystalline aggregate, the spatial orientation of the basal planes of an individual crystal is defined by the orientation of its crystallographic $c$-axis, which is normal to the basal planes and is the axis of hexagonal symmetry in an ice crystal. During the high-strain deformation, typical of the polar ice sheets, patterns of preferred crystal $c$-axis orientations (often referred to as crystal orientation fabrics) evolve to accommodate crystallographic slip on basal planes. This leads to the development of polycrystalline anisotropy and an associated reduction in the ice viscosity (e.g. Budd and Jacka, 1989; Cuffey and Paterson, 2010). A physically accurate parameterization of these effects is fundamental to improving the predictive capability of ice sheet models, in order to (i) more accurately quantify ice sheet contributions to global sea level and (ii) reduce uncertainty in the depthage relationships used to constrain ice core palaeoclimate records.

Various numerical flow relations for ice, where the effect of $c$-axis orientations on the flow properties is explicitly included as a rheological variable, have been proposed (e.g. Lile, 1978; van der Veen and Whillans, 1994; Azuma and Goto-Azuma, 1996; Svendsen and Hutter, 1996; Thorsteinsson, 2002; Gillet-Chaulet et al., 2005; Placidi et al., 2010). In such flow relations the anisotropic viscosity of a polycrystalline aggregate is obtained from the orientation relationship between the grain $c$-axes and the stress configuration, or some parameterization of these orientation effects. In general such flow relations are not suited to implementation within models used to simulate the large-scale evolution of the polar ice sheets, being either too numerically complex or lacking the ability to accurately describe anisotropic flow effects (e.g. Treverrow et al., 2015). The importance of a realistic description of anisotropic ice rheology to accurate modelling of ice sheet dynamics has been demonstrated in regionalscale ice sheet models (e.g. Seddik et al., 2011; Wang et al., 2012; Zwinger et al., 2014), where the task of determining the three dimensional distribution of stresses within an ice mass is computationally tractable.

Accordingly, the ongoing value of physically motivated, yet complex flow relations lies in their role as tools to understand intra- and intercrystalline microdeformation, recovery and recrystallization processes (e.g. Montagnat et al., 2014b; Faria et al., 2014b). In turn, these models can inform the development of parameterizations of key rheological variables, which are necessary for the specification of numerically simpler ice flow relations. The continued development and validation of physically accurate flow relations for ice sheet modelling requires observations of ice microstructures from deep drilled ice cores, including the patterns of preferred crystal $c$-axis orientations within an ice mass. Such data can be obtained from the analysis of thin section samples. These measurements are made routinely in ice core and laboratory deformation studies investigating the links be-

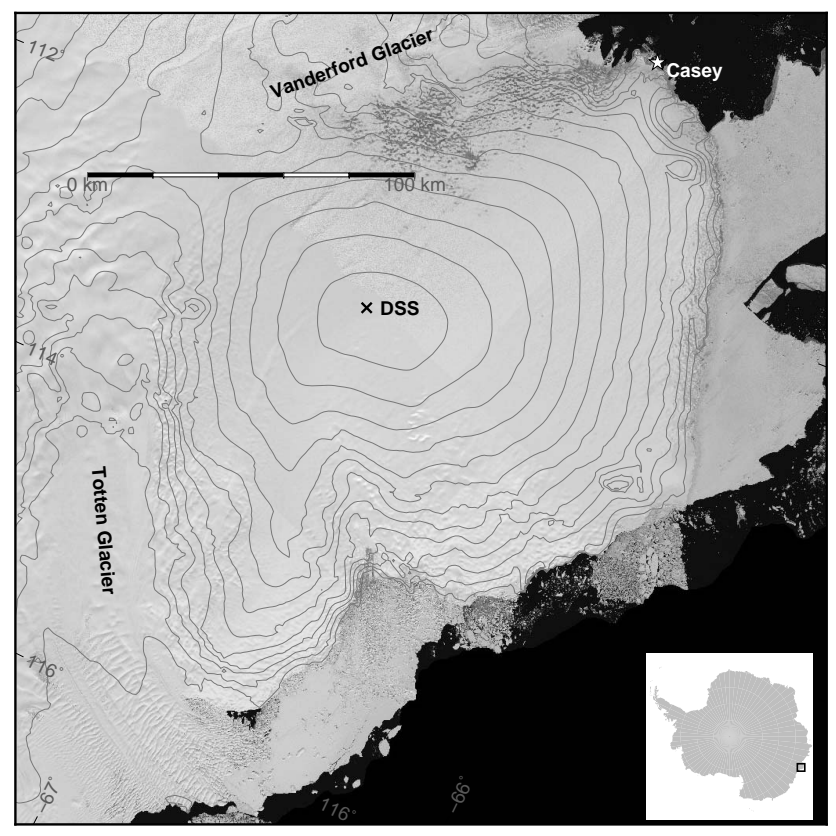

Figure 1. Location of the drilling site for the $1196 \mathrm{~m}$ Dome Summit South (DSS) ice core on Law Dome, East Antarctica. The drill site is $4.7 \mathrm{~km} \mathrm{SSW}$ from the dome summit. The background image is from the Landsat Image Mosaic of Antarctica (Bindschadler et al., 2008) and 100 m elevation contours from Bamber et al. (2009).

tween the microstructure of ice and the large-scale dynamics of ice sheets (e.g. Gow and Williamson, 1976; Russell-Head and Budd, 1979; Gao and Jacka, 1987; Pimienta et al., 1987; Budd and Jacka, 1989; Tison et al., 1994; Li et al., 2000; Durand et al., 2007; Gow and Meese, 2007a; Treverrow et al., 2012; Montagnat et al., 2014a).

Here we present ice crystallographic $c$-axis orientation and grain size data from the Dome Summit South (DSS) ice core drilled $4.7 \mathrm{~km} \mathrm{SSW}$ of the summit of Law Dome, East Antarctica $\left(66.770^{\circ} \mathrm{S}, 112.807^{\circ} \mathrm{E}\right.$; Table 1; Li, 1995 ; Morgan et al., 1997; Li et al., 1998; Morgan et al., 1998). This $1195.9 \mathrm{~m}$ ice core was drilled by the Australian Antarctic Division during the austral summers of 1987-1988 to 19921993. Law Dome (Fig. 1) is a coastal ice cap $\sim 200 \mathrm{~km}$ in diameter with a summit elevation of $1370 \mathrm{~m}$. Grounded ice at Law Dome extends to lower latitudes than any other region of the Antarctic Ice Sheet, with the exception of the northern Antarctic Peninsula. As such, the local climate has a strong maritime influence and the summit region of Law Dome experiences a high rate of annual snow accumulation and relatively low wind speeds (Bromwich, 1988; Curran et al., 1998). The ice dynamics of Law Dome are relatively independent of the adjoining East Antarctic Ice Sheet as it is isolated from the Aurora subglacial basin by the Vanderford trench (Pfitzner, 1980; Roberts et al., 2011).

A primary consideration in the selection of the DSS drilling site was the identification of a location where the 
Table 1. DSS borehole site and ice core information (Morgan et al., 1997, 1998).

\begin{tabular}{ll}
\hline Latitude & $66.770^{\circ} \mathrm{S}$ \\
Longitude & $112.807^{\circ} \mathrm{E}$ \\
Surface elevation & $1370 \mathrm{~m}$ \\
Ice thickness & $1220 \pm 20 \mathrm{~m}$ \\
Borehole depth & $1195.9 \mathrm{~m}$ \\
Borehole ice-equivalent depth & $1174.07 \mathrm{~m}$ \\
Mean annual surface temperature & $-21.8^{\circ} \mathrm{C}$ \\
Bottom of borehole temperature & $-6.9^{\circ} \mathrm{C}$ \\
Annual ice accumulation & $0.69 \mathrm{~m} \mathrm{a}^{-1}$ \\
Ice surface velocity and bearing & $(2.04 \pm 0.11) \mathrm{ma}^{-1}$ \\
& at $225^{\circ} \pm 3^{\circ}$ \\
& $(3.22 \pm 0.016) \times 10^{-4} \mathrm{a}^{-1}$ \\
Surface GPS strain rate & \\
(parallel to surface flow direction) & \\
Surface GPS strain rate & $(4.50 \pm 0.027) \times 10^{-4} \mathrm{a}^{-1}$ \\
(normal to surface flow direction) & \\
\hline
\end{tabular}

rates of ice deformation, and those upstream, were insufficient to significantly disturb the chronology of annually accumulated ice layers. Ice-penetrating radar was used to assist site selection by identifying locations where the regional bedrock topography was least likely to have created flowinduced folding or other discontinuities in the ice laminae (Hamley et al., 1986; Etheridge, 1990; Morgan et al., 1997). The well-preserved layering at the DSS site, combined with the maritime influence on the orographically driven high accumulation rates on Law Dome has made the DSS ice core a valuable resource for generating mid- and high-latitude palaeoclimate proxy records from the Holocene and Last Glacial Maximum (LGM; van Ommen and Morgan, 2010; Plummer et al., 2012; Vance et al., 2013; Roberts et al., 2015; Vance et al., 2015).

\section{Methods}

The upper $96 \mathrm{~m}$ of the DSS core was obtained with a $270 \mathrm{~mm}$ diameter thermal drill during the 1987-1988 austral summer and the borehole was cased to a depth of $82 \mathrm{~m}$. In the following season a drill shelter was constructed over the borehole and thermal drilling continued to $117 \mathrm{~m}$ depth using a smaller $120 \mathrm{~mm}$ drill. Over the 1989-1990 and 1990-1991 field seasons the electromechanical drill used to recover the main DSS ice core was assembled and commissioned (Morgan et al., 1997). This drill was based on a modified Danish ISTUK design (Gundestrup et al., 1984) and produced $100 \mathrm{~mm}$ diameter core sections. Coring to a depth of $553.9 \mathrm{~m}$ was completed during the 1991-1992 field season and in the following season drilling continued to the final depth of $1195.6 \mathrm{~m}$. Coring was halted when the cutting head of the drill was damaged through contact with a rock, which was not recovered in the core. This final core section was found to contain other, small rock fragments. The estimated total ice thickness of $1220 \pm 20 \mathrm{~m}$ at the DSS site was determined using ice-penetrating radar (Morgan et al., 1997). Based on this value, the bedrock is expected to be within 5 to $45 \mathrm{~m}$ of the bottom of the borehole. The DSS core was recovered in 1261 sections with a mean length of $0.949 \mathrm{~m}$ and standard deviation $\sigma=0.092 \mathrm{~m}$.

\subsection{Thin section preparation}

Ice crystal $c$-axis orientation and grain size measurements were made on horizontal thin sections obtained from 185 of the 1261 individual ice core sections that make up the DSS core. These samples were obtained at intervals of $\sim 5$ to $6 \mathrm{~m}$ between the depths of 117.1 and $1195.9 \mathrm{~m}$. The thin sections were prepared during drilling operations in order to minimize the time between core recovery and analyses. Typically, the interval between drilling and thin section preparation was $<1$ to $16 \mathrm{~h}$, with a mean of $\sim 3 \mathrm{~h}$ (Li et al., 1998). This procedure reduced the potential for any post-drilling microstructural evolution to adversely influence the analyses. Furthermore, all sample preparation and analyses were conducted in a sub-surface laboratory, excavated adjacent to the drilling pit. Since the temperature in the laboratory was approximately equivalent to the mean annual surface temperature of $-21.8^{\circ} \mathrm{C}$ all analyses were conducted at temperatures below the in situ values. Working at these low temperatures reduced the potential for post-drilling microstructural modification. Conducting the microstructural observations at the drilling site also eliminated the risk of damaging the samples during long-term storage and/or transportation to laboratories outside Antarctica.

The $\sim 10 \mathrm{~mm}$ thick horizontal sections were cut perpendicular to the long axis of the ice core. These samples were sanded to a smooth finish using wet-and-dry type abrasive paper mounted on a flat board before being thermally bonded to glass slides. Following mounting, the thickness of the samples was reduced to between 0.4 and $0.7 \mathrm{~mm}$ using a microtome. Thicknesses towards the lower end of this range were necessary to clearly resolve individual grains in those samples with a smaller mean grain size. Two different microtomes were used to reduce the sample thickness. An electromechanical microtome, based on a modified electric woodworking plane, was better suited to rapidly reducing the section thickness while a manually operated sledge microtome provided superior control when making the final fine adjustments to the section thickness. The sledge microtome was also found to be less likely to induce fracturing when working with the extremely brittle ice encountered at depths from 552 to $1190 \mathrm{~m}$.

\subsection{Crystallographic $c$-axis measurements}

The crystal $c$-axis orientations were measured manually using a universal (Rigsby) stage following the standard techniques described by Langway Jr. (1958). The instrument used was modified to provide digital orientation data for each 
grain examined (Morgan et al., 1984). These output data are corrected for differences in the refractive indices of ice and air using the values of Langway Jr. (1958).

As outlined by Langway Jr. (1958), several potential sources of error can influence the orientations determined using a universal stage. These include (i) uncertainty in precisely locating the extinction position for high-angle orientations, (ii) systematic operator bias due to not correctly aligning the viewing direction (line of sight) with the crystal $c$ axis being examined and (iii) instrument backlash due to inherent and finite non-zero tolerances that influence the reproducibility of measurements. Langway Jr. (1958) estimates that the latter may contribute to 1 to $2^{\circ}$ of measurement error and that the combined maximum error from all sources will typically be $<5^{\circ}$, particularly when measurements are made with consistently high levels of care. Because the universal stage used to measure the DSS ice core crystal orientations employs sensors to determine the position of the instrument axes, incorrect reading of the axis scales is eliminated as a source of error in these data. An upper limit of the possible angular error in azimuth or colatitude data is $\pm 5^{\circ}$.

Due to the time-consuming procedure required to manually determine $c$-axis orientations using the universal stage in a challenging work environment, a maximum of $\sim 100$ orientations were recorded from each thin section, including those fine-grained samples where the total number of grains, $N$, within the thin section was $\gg 100$. Sampling bias, including the preferential selection of larger grains was avoided by (i) tracking those grains that had been measured on a polaroid image of the thin section and (ii) selecting a continuous (i.e. gap-free) set of neighbouring grains from within an enclosed region so that each grain had at least one neighbour within the region of interest. Analyses were completed at the rate of $\sim 100 c$-axis orientations per $3 \mathrm{~h}$. For those thin sections containing larger grains with $N \ll 100, c$-axis orientations were recorded for all identifiable grains. For each of the 185 DSS thin sections, the number of measured $c$-axis orientations was $5<N<111$, with a median of $N=100$.

During the 1990s when the DSS ice core was drilled, the measurement of ice crystal $c$-axis orientations using a universal stage, as used in this study, was considered state of the art. In the time since these measurements were made considerable technological advances in the instruments available to measure crystal orientations have occurred (e.g. Yun and Azuma, 1999; Wilen et al., 2003; Wilson et al., 2007; Wilson and Peternell, 2011). Modern instruments provide several benefits over the universal stage including (i) higher resolution, enabling small-scale differences in crystallographic orientations within individual grains to be detected, (ii) the ability to spatially map $c$-axis orientations, (iii) automated operation and a significantly higher speed of determining orientations, and (iv) lower levels of uncertainty in both $c$ axis azimuth and colatitude. Since analytical techniques for both microstructural and chemical analyses of ice cores are destructive, only a small proportion of the original ice core cross section remains over the full length of the core. This remainder is insufficient to allow a detailed reanalysis of $c$ axis orientations and grain size using a modern instrument. Additionally, the remaining core material is prioritized for chemical reanalyses, should any be required.

\subsection{Crystal size measurements}

The mean grain size was determined from polaroid photographs of the thin sections. A purpose-built stand was used to position the thin sections between orthogonal plane polarizing filters. This allowed individual grains to be visually distinguished by their orientation-dependent birefringence colours. A polaroid camera, mounted directly to the stand, captured high-quality colour images on a $1: 1$ scale. A transparent cover plate, etched with a $10 \mathrm{~mm}$ square grid, was placed over the samples to superimpose a grid of the same dimensions onto the polaroid images.

The mean grain area was calculated from the number of grains contained within a specified area of the thin section. The region of interest was determined by placing a sheet of low-opacity tracing paper over the polaroid image; its transparency allowed an irregularly shaped region to be traced along grain boundaries and the number of grains within this region to be counted. A digitizing tablet was used to accurately determine the area of the irregularly shaped region marked on the tracing paper. Typically these areas for grain size analysis varied between 880 and $2400 \mathrm{~mm}^{2}$ ( $\left.\mathrm{Li}, 1995\right)$. The area, in conjunction with the total number of grains counted within the traced region, was used to calculate an arithmetic mean estimate of cross sectional grain area. Figures incorporating the depth profile of mean grain size at the DSS site have been presented previously (e.g. Morgan et al., 1997; Li et al., 1998), but until now the data have not been easily accessible.

Uncertainty in the mean grain area estimates may originate from errors in counting the number of grains within the traced region or when determining the area of the traced region using a digitizing tablet. For digitizing tablets, instrument-related planimetric position errors are typically $\ll 1 \mathrm{~mm}$ and are negligible in comparison with any operator error. Consequently, the uncertainty in the calculated mean grain areas is strongly related to both operator skill and consistency.

To determine an upper limit on the uncertainty in the calculated mean area we assume the maximum error in the position of any section of the traced boundary enclosing the counted grains to be $\sim \pm 1 \mathrm{~mm}$. Applying this level of uncertainty to the entire perimeter of the traced region results in an area uncertainty of $\sim \pm 10 \%$. In most cases this upper limit on uncertainty will be an overestimate of the true uncertainty; however, precise estimates of uncertainty were not made at the time of measurement, so we are unable to calculate the specific error for the individual mean grain areas. 
Some further general comments on the methods used to specify the grain size of polycrystalline materials are warranted. While thin section analysis is the only practical means of routinely estimating grain area, it only provides a two dimensional estimate of a volumetric object. Furthermore, all methods used to determine grain areas from thin sections underestimate the actual grain dimensions because the sectioning plane almost never intersects each grain across its plane of maximum cross-sectional area (e.g. Feltham, 1957; Gow, 1969). There are a variety of techniques for determining the grain size of polycrystalline materials from thin sections that also take the sectioning bias into account.

In the methods described by Krumbein (1935), Pickering (1976), Baker (1982) and Jones and Chew (1983), grain size is estimated from the mean length of the maximum linear intercept through a grain. This requires assumptions to be made regarding the grain shape and distribution of grain sizes. Stephenson (1967) and Gow (1969) calculated mean grain areas based on the measurement of minimum and maximum axial dimensions of individual grains. To further reduce the effect of sectioning on underestimating the threedimensional distribution of grain size, Gow (1969) restricted measurement to the 50 largest grains identified within a thin section; however, the results obtained using this technique are sensitive to the number of grains within the section.

Methods of grain size analysis that require measurement of linear intercepts through grains (e.g. Krumbein, 1935; Stephenson, 1967; Gow, 1969; Baker, 1982) are time consuming and were considered incompatible with the program of obtaining crystal $c$-axis orientation and size measurements during drilling and field analysis of the DSS ice core. As noted by Jacka (1984), the mean linear intercept methods of grain size estimation, and in particular those assumptions that attempt to correct for sectioning effects, may be inappropriate when the actual distributions of grain size and shape are either unknown or variable. In such cases Jacka (1984) suggests that the arithmetic mean grain area, based on the crystal count per unit area, is a superior estimate of grain size. For polycrystalline metals, Feltham (1957) has demonstrated that the three-dimensional distribution of grain size can be represented by the planar distribution obtained from thin sections provided that grain shape is not correlated with the crystallographic $c$-axis orientation. This result is directly applicable to other polycrystalline materials, including ice, for which the grain size does not vary with the orientation of the sectioning plane. In this case the mean grain area (count per unit area) can be considered representative of the corresponding volumetric grain size. While the mean grain areas presented here will underestimate the corresponding threedimensional grain size due to the aforementioned sectioning effects, the data remain valuable as they are indicative of the mean grain size at a specific depth and also describe the evolution in grain size as a function of depth.

The single mean grain size measurements per thin section included in this data set provide a coarse representation of grain size in comparison to the data that can be obtained using modern instruments (e.g. Durand et al., 2006). Since the original thin sections used for $c$-axis and mean grain size measurements no longer exist, higher-resolution analyses using such an instrument are not possible. For those interested in extracting additional microstructural information, such as the distribution of grain size and/or shape, digital analysis of the original thin section images is a possibility. A full set of polaroid photographs of the DSS ice core thin sections remain in existence and these can be accessed by contacting the authors via the Australian Antarctic Data Centre (http://data.antarctica.gov.au).

\section{Data}

Measurements of $c$-axis orientations and mean grain area were made on 185 horizontal thin sections obtained from the upper end of the selected core sections. The reported depth for each thin section is that from the ice sheet surface to the top of the core section. In the upper part of an ice sheet the observed ice density increases with depth as snow undergoes a transition to firn and then glacial ice. The very slow flow of glaciers and ice sheets is the result of gravity-induced deformation that is dependent upon several factors, including the ice sheet geometry (ice thickness, surface elevation, bedrock topography) and the ice density (e.g. Cuffey and Paterson, 2010).

In the numerical models used to simulate ice sheet dynamics, it is more practical to specify a constant ice density when calculating the magnitude of the stresses driving ice flow. The assumption of a constant density is reasonable for ice sheets where ice thicknesses may be hundreds or thousands of metres; however, it is necessary to convert any data sets used for calibration or validation of the models to an ice-equivalent depth scale. Similarly, the interpretation and application of ice core chemistry in palaeoclimate studies is simplified by conversion to an ice-equivalent depth scale. This is particularly convenient when synchronizing multiple ice core records from different geographical locations. The crystal $c$-axis orientation and mean grain area data are reported on both actual and ice-equivalent depth scales. At an actual depth $\chi$, the ice-equivalent depth

$\mathrm{d}(\chi)=\int_{0}^{\chi} \frac{\rho\left(\chi^{\prime}\right)}{\rho_{\text {ice }}} \mathrm{d} \chi^{\prime}$,

where $\rho\left(\chi^{\prime}\right)$ is the firn and ice density profile and $\rho_{\text {ice }}=917 \mathrm{~kg} \mathrm{~m}^{-3}$ is the maximum ice density (Roberts et al., 2015). The depth-varying $\rho\left(\chi^{\prime}\right)$ is obtained from an empirical fit to density measurements from the DSS core (van Ommen et al., 1999). The firn to ice transition marks the depth where the interconnected pore space between individual grains is closed off, forming discrete bubbles and $\rho_{\text {ice }} \sim 830 \mathrm{~kg} \mathrm{~m}^{-3}$. At DSS this transition 
Table 2. Description of the data fields in each row of the csv formatted DSS ice core $c$-axis orientation and mean grain area data file, DSS_fabric_data.csv

\begin{tabular}{|c|c|}
\hline Name & Identifier of the DSS ice core section \\
\hline Longitude & $\begin{array}{l}\text { DSS ice core site longitude } \\
\text { (decimal degrees) }\end{array}$ \\
\hline Latitude & $\begin{array}{l}\text { DSS ice core site latitude } \\
\text { (decimal degrees) }\end{array}$ \\
\hline Number_of_c_axes & $\begin{array}{l}\text { the number of } c \text {-axes in the } \\
\text { section identified by "name" }\end{array}$ \\
\hline Depth_actual & $\begin{array}{l}\text { the actual depth measured downwards } \\
\text { from the ice sheet surface to the top } \\
\text { of the core section (metres) }\end{array}$ \\
\hline Depth_ice_equivalent & $\begin{array}{l}\text { "depth_actual" converted to an } \\
\text { ice-equivalent depth (metres) }\end{array}$ \\
\hline Section_orientation & $\begin{array}{l}\text { thin section orientation ("vertical" or } \\
\text { "horizontal") }\end{array}$ \\
\hline Mean_horz_grain_area & $\begin{array}{l}\text { mean grain area measured from } \\
\text { horizontal thin sections (perpendicular } \\
\text { to the vertical ice core axis; } \mathrm{mm}^{2} \text { ) }\end{array}$ \\
\hline Grain_index & $\begin{array}{l}\text { the identifier of the data point within } \\
\text { the thin section }\end{array}$ \\
\hline Colatitude & $\begin{array}{l}c \text {-axis orientation colatitude } \\
\text { (degrees, lower hemisphere projection) }\end{array}$ \\
\hline Azimuth & $\begin{array}{l}c \text {-axis orientation azimuth } \\
\text { (degrees, lower hemisphere projection) }\end{array}$ \\
\hline
\end{tabular}

occurs at $\sim 40 \mathrm{~m}$ depth. Below this depth density variations are negligible and the ice-equivalent depth offset from the actual depth has a constant value of $-21.53 \mathrm{~m}$ (van Ommen et al., 2004).

\subsection{Crystal orientation and mean grain size data products}

The combined crystal $c$-axis orientation and mean grain size data are provided in two formats.

1. A single comma-separated value (csv) file containing $c$ axis orientation information for all grains in each of the 185 thin sections analysed. Each row in the file contains $c$-axis orientation data for an individual grain expressed in polar coordinates (azimuth and colatitude), the mean grain size calculated for the parent thin section and other information relevant to the measurements. See Table 2 for a full description of the fields in the data set.

2. A MATLAB ${ }^{\mathrm{TM}}$ structure array containing $c$-axis vectors expressed in both polar and Cartesian coordinates (MATLAB and Statistics Toolbox Release 2015b, The MathWorks Inc., Natick, Massachusetts, United States). Other data included in the structure array are described in Table 3. Some derived quantities are also presented in the structure array. These include the eigenvalues $a_{i}$ $(i=1,2,3)$ of the second-order $c$-axis orientation tensor, $\boldsymbol{\Lambda}$, and its corresponding eigenvectors $\boldsymbol{v}$.

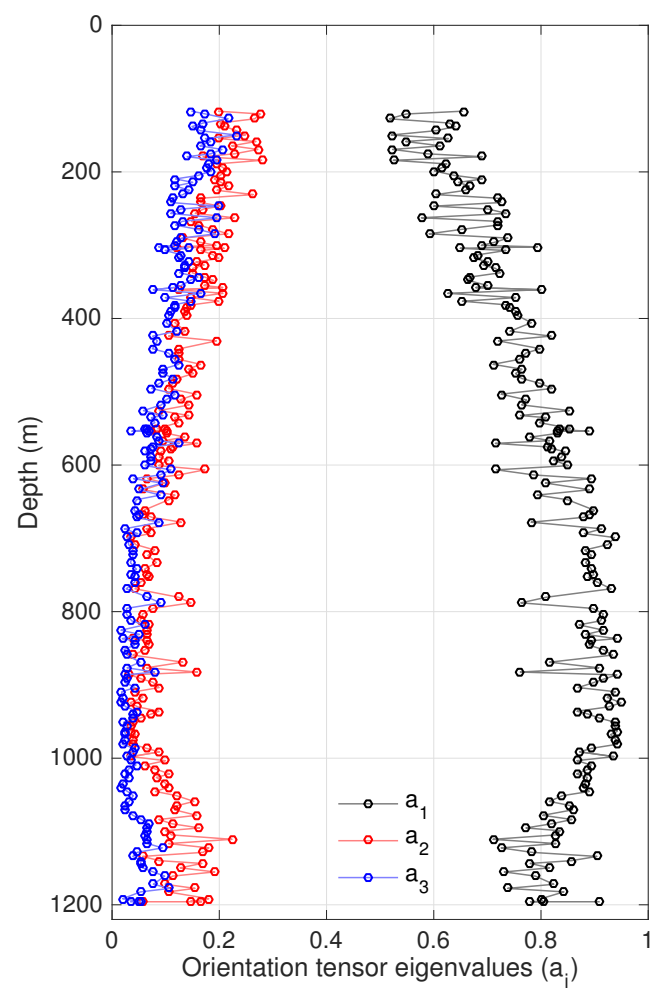

Figure 2. Variation in the eigenvalues, $a_{i}$, of the second-order orientation tensor, $\boldsymbol{\Lambda}$, as a function of actual depth. See text for details of $a_{i}$.

The crystallographic $c$ axis and mean crystal area data are summarized as a function of actual depth in Figs. 2 and 3 respectively. The pattern of $c$-axis orientations can be expressed by the eigenvalues, $a_{i}$, of the $c$-axis orientation tensor, $\boldsymbol{\Lambda}$ (Fig. 2, Woodcock, 1977). Calculation of the orientation tensor requires transformation of the $c$-axis data from polar to Cartesian coordinates. For a population of $N c$-axis orientation vectors the normalized form of $\boldsymbol{\Lambda}$ is defined in terms of their $N$ outer products:

$\Lambda=\frac{\sum_{i=1}^{N} \hat{c}_{i} \otimes \hat{c}_{i}}{N}$.

The eigenvalues are related as $a_{1}+a_{2}+a_{3}=1$, where by convention $0 \leq a_{3} \leq a_{2} \leq a_{1} \leq 1$. The eigenvalues provide a statistical representation of the pattern of $c$-axis orientations as each $a_{i}$ defines the degree of clustering about its corresponding eigenvector, $\hat{v}_{i}$. The distribution of orientations is minimized about the eigenvector $\hat{v}_{1}$ of the maximum eigenvalue, $a_{1}$, whilst $\hat{v}_{3}$ is the direction about which the distribution is largest. The distribution of orientations becomes smaller, i.e. fabrics become stronger or more clustered as $a_{1} \rightarrow 1$, whilst for an isotropic (random) distribution of orientations $a_{1}=a_{2}=a_{3}=\frac{1}{3}$. As the area of individual grain orientations was not recorded, volume weighting of the ori- 


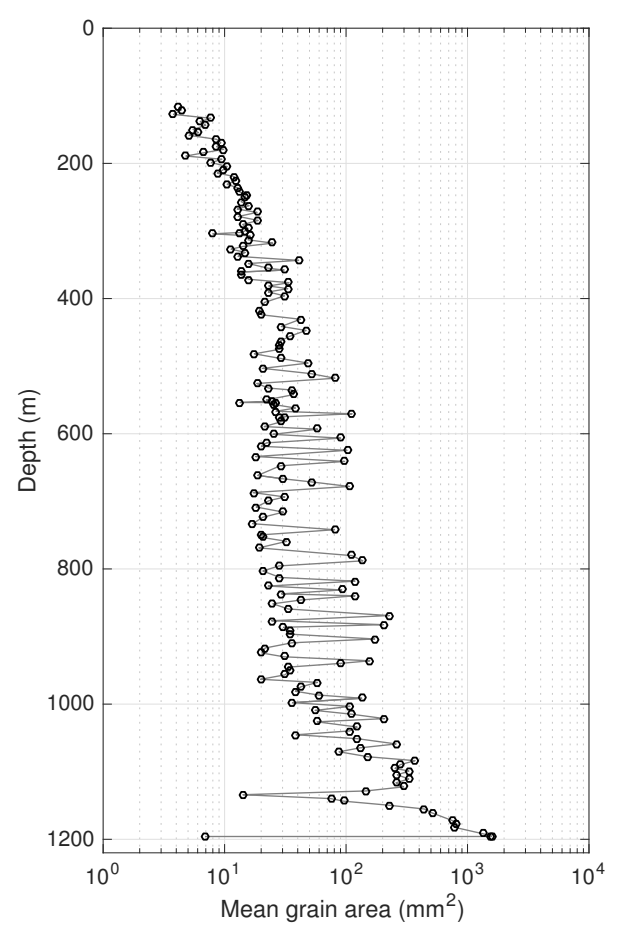

Figure 3. Variation in the DSS ice core mean grain area with actual depth. See text for details of the mean grain area calculation. All values were determined from horizontal thin sections (after Li et al., 1998).

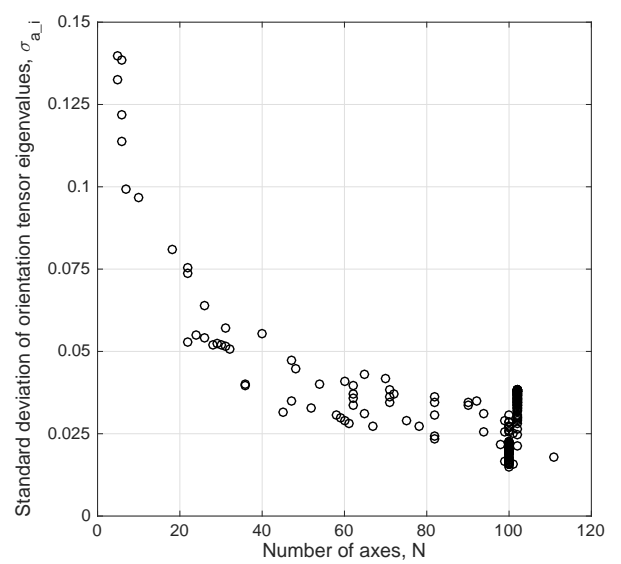

Figure 4. Variation of the standard deviation, $\sigma_{a_{i}}^{\mathrm{p}}$, of the eigenvalues of the second-order orientation tensor with $N$, the number of $c$-axis orientations measured in each of the 185 thin sections. Values of $\sigma_{a_{i}}^{\mathrm{p}}$ are calculated according to Eq. (3). The median value of $N=100$ and there are 50 measurements at $N=100$ and 70 at $N=102$.

entation data (e.g. Durand et al., 2006) was not possible and all orientations contribute equally to $\boldsymbol{\Lambda}$ (Fig. 2 ).

Allowances can be made for the distribution of grain sizes encountered in polycrystalline materials by weighting the contribution of individual $c$-axis orientations accord-
Table 3. Format of the MATLAB ${ }^{\mathrm{TM}}$ R2015b structure array, DSS_fabric_data.mat, which contains DSS ice core crystal$\operatorname{lographic} c$-axis orientation and mean grain area data.

\begin{tabular}{|c|c|}
\hline Name & DSS ice core section name \\
\hline C_cartesian & $\begin{array}{l}{[N \times 3] \text { array of Cartesian } c \text {-axis }} \\
\text { unit vectors; } \mathrm{N} \text { is the number of } \\
c \text {-axes in the section }\end{array}$ \\
\hline C_polar & $\begin{array}{l}{[N \times 2] \text { array of polar } c \text {-axis vectors; }} \\
\text { colatitude and azimuth (degree) }\end{array}$ \\
\hline Depth_actual & $\begin{array}{l}\text { the actual depth measured downwards } \\
\text { from the ice sheet surface to the top } \\
\text { of the core section (metres) }\end{array}$ \\
\hline Depth_ice_equivalent & $\begin{array}{l}\text { "depth_actual" converted to an } \\
\text { ice-equivalent depth (metres) }\end{array}$ \\
\hline Mean_horz_grain_area & $\begin{array}{l}\text { mean grain area measured from } \\
\text { horizontal thin sections (perpendicular } \\
\text { to the vertical ice core axis; } \mathrm{mm}^{2} \text { ) }\end{array}$ \\
\hline Orientation_tensor_a & $\begin{array}{l}\text { eigenvalues, } \boldsymbol{a} \text {, of the } 2 \text { nd order } \\
\text { orientation tensor, } \boldsymbol{\Lambda}\end{array}$ \\
\hline Orientation_tensor_V & $\begin{array}{l}\text { eigenvectors, } \boldsymbol{v} \text {, of the } 2 \text { nd order } \\
\text { orientation tensor, } \boldsymbol{\Lambda}\end{array}$ \\
\hline
\end{tabular}

ing to their area in quantitative descriptions of fabric, such as $\boldsymbol{\Lambda}$. The pixel-scale orientation data provided by modern automated fabric analysers makes area weighting of $c$ axis orientations a routine aspect of microstructural analysis. In turn, this allows for an improved representation of microstructures extracted from thin sections. For example, Gagliardini et al. (2004) note that with area weighting of orientations, the mean error in second-order orientation tensor-based representations of fabric (e.g. Woodcock, 1977; Durand et al., 2006) may be up to $\sim 2.5$ times less than that for equally weighted orientations. Notwithstanding the restriction of this data set to equal weighting of orientations, it represents a valuable resource for the quantitative assessment of ice flow relations and microstructural evolution.

For a population of $N c$-axis orientations, the contribution of the population size to the standard deviation of the orientation tensor eigenvalues, $\sigma_{a_{i}}^{\mathrm{p}}$, can be estimated from,

$\sigma_{a_{i}}^{\mathrm{p}}=\left[-1.64 \times\left(a_{1}\right)^{2}+1.86 \times a_{1}-0.14\right] \times \frac{1}{N^{1 / 2}}$.

Equation (3) was derived by Durand et al. (2006) from the statistical analysis of multiple subsamples of $100<N<$ 1000 orientations from a parent population of $10^{4}$ orientations. Values of $\sigma_{a_{i}}^{\mathrm{p}}$ calculated using Eq. (3) for each of the 185 thin sections in the DSS data set are presented in Fig. 4 and clearly demonstrate the influence of $N$ on the variability in fabric statistics; $\sigma_{a_{i}}^{\mathrm{p}}$ ranges from 0.0148 up to a maximum of 0.140 for the lowest values of N. As expected from Eq. (3), $\sigma_{a_{i}}^{\mathrm{p}}$ decreases with larger $N$, and for the majority of the DSS data set, where $N>40$ the estimated variability in $\sigma_{a_{i}}^{\mathrm{p}}$ is rela- 

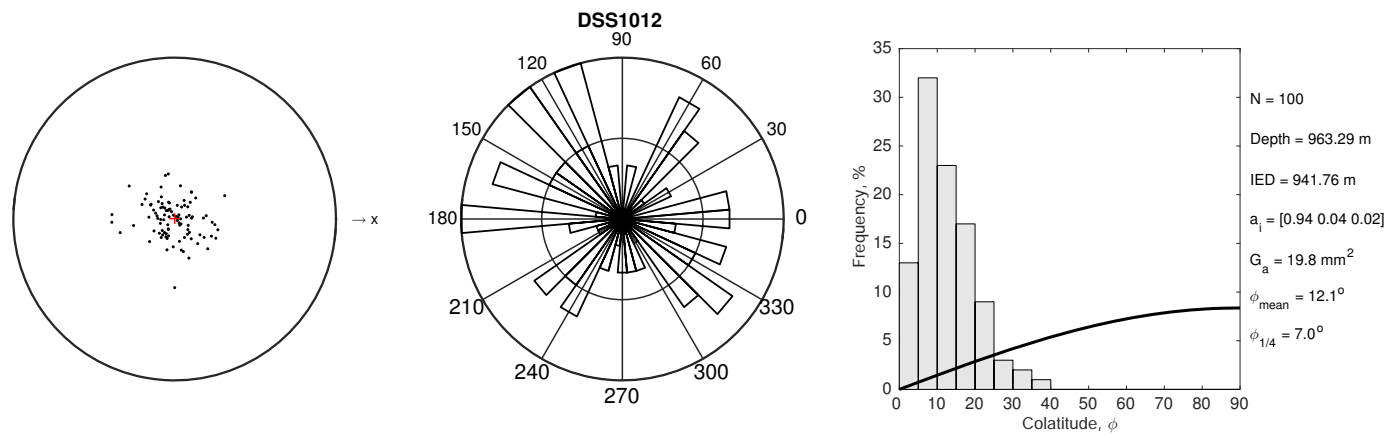

Figure 5. Sample of the thin-section figures included with the data set. From left to right: (i) lower hemisphere $c$-axis Schmidt plot, (ii) a rose plot of the $c$-axis azimuth distribution and (iii) a histogram of the $c$-axis colatitude, $\phi$. The colatitude histograms are annotated with the number of grains, $N$, in the distribution; the actual ice depth; ice-equivalent depth (IED); eigenvalues, $a_{i}$, of the orientation tensor $\Lambda$; mean grain area, $G_{\mathrm{a}}$; mean colatitude, $\phi_{\text {mean }}$; and the cone angle containing the first quartile of $c$-axis colatitudes, $\phi_{\frac{1}{4}}$.

tively low, as indicated by mean and median values of 0.0355 and 0.0337 respectively.

A component of the observed variability in the DSS fabric and mean grain size data (Figs. 2 and 3) over small vertical distances (e.g. $\sim 5-20 \mathrm{~m}$ ) is due to the influence of ice chemistry, impurities and the dynamic conditions at the drilling site on microstructural evolution. This variability is therefore an inherent feature of the data and similar effects have been reported for other Antarctic and Greenland ice cores (e.g. Durand et al., 2007; Gow and Meese, 2007b).

Estimating the magnitude of impurity effects on the variability in derived microstructural parameters is not possible with the DSS data set; however, observations from Morgan et al. (1997, Fig. 8) indicate that localized variability in the fabric strength that is superimposed on the large-scale pattern of fabric evolution with depth corresponds to changes in the mean grain size. In particular, thin sections with stronger fabrics (lower mean $c$-axis colatitude) tended to have smaller mean grain sizes than adjacent thin sections with weaker fabrics and correspondingly larger mean grain sizes. Based on analysis of the insoluble impurity content in the DSS ice core, Li et al. (1998, Fig. 2) suggest that locally high levels of microparticles are associated with a refinement of the mean grain size and the preservation of stronger crystal orientation fabrics due to a retardation of recrystallization processes.

The data set made available for download at the Australian Antarctic Data Centre also includes graphical representations of the $c$-axis orientations. For each thin section a figure containing three subfigures is provided (see Fig. 5). These include a lower-hemisphere Schmidt plot of the $c$-axes; a rose plot of the distribution of $c$-axis azimuth, $\theta$; and a histogram of the $c$-axis colatitude, $\phi$. The colatitude histograms are annotated with the number of grains, $N$, in the distribution; the actual depth; ice-equivalent depth (IED); eigenvalues, $a_{i}$, of the orientation tensor $\boldsymbol{\Lambda}$; mean grain area, $G_{\mathrm{a}}$; mean colatitude, $\phi_{\text {mean }}$; and the cone angle containing the first quartile of $c$-axis colatitudes, $\phi_{\frac{1}{4}}$.

\section{Summary}

Observations of ice microstructures from deep drilled polar ice cores play a vital role in the development and validation of ice flow relations for numerical ice sheet modelling. In particular, measurements of the patterns of ice crystal $c$-axis orientations and grain size from thin sections, obtained at regular depth intervals along an ice core, provide detailed information on the relationships between large-scale ice sheet dynamics and microstructural evolution.

Measurements of crystal $c$-axis orientations and grain size were obtained from the Dome Summit South (DSS) ice core, drilled at Law Dome, East Antarctica. The data were obtained from 185 horizontal thin sections taken at intervals of approximately 5 to $6 \mathrm{~m}$ between the depths of 117 and $1196 \mathrm{~m}$. All $c$-axis orientation measurements were made using a universal (Rigsby) stage. The number of $c$-axis orientations recorded in each thin section varied according to the grain size and ranged from a minimum of 5 up to 111 , with a median value of 100 . For each thin section the arithmetic mean grain area was also determined. These data are made available in two formats: (i) as a single csv formatted file containing all $c$-axis orientations (in polar coordinates) and mean grain area for each of the 185 thin sections, plus other data relevant to the DSS drilling site, and (ii) as a MATLAB ${ }^{\mathrm{TM}}$ structure array containing the $c$-axis and grain size data for each thin section and derived quantities, including the eigenvalues and eigenvectors of the second-order orientation tensor. These data are available free of charge from the Australian Antarctic Data Centre (http://data.antarctica.gov.au) and are referenced by doi:10.4225/15/5669050CC1B3B.

Acknowledgements. The Australian Antarctic Division provided funding and logistical support for drilling the DSS ice core and subsequent data analysis through projects ASAC 15, AAS 757 and AAS 4289. The authors gratefully acknowledge the contribution of all participants in the Australian National Antarctic 
Research Expeditions associated with retrieval of the DSS ice core. Preparation of the data for archiving was supported by the Australian Government Cooperative Research Centres Programme through the Antarctic Climate and Ecosystems Cooperative Research Centre (ACE CRC). Discussions with J. L. Roberts assisted with data management and manuscript preparation. B. Raymond assisted with data control and hosting. We are thankful for comments from Maurine Montagnat and an anonymous reviewer, who assisted in improving the manuscript. Adam Treverrow thanks R. C. Warner for stressing the importance of making these data widely available to the glaciological community.

Edited by: O. Eisen

\section{References}

Alley, R. and Joughin, I.: Modeling ice-sheet flow, Science, 336, 551-552, doi:10.1126/science.1220530, 2012.

Azuma, N. and Goto-Azuma, K.: An anisotropic flow law for ice sheet ice and its implications, Ann. Glaciol., 23, 202-208, 1996.

Baker, R.: A flow equation for anisotropic ice, Cold Reg. Sci. Technol., 141-148, 1982.

Bamber, J. L., Gomez-Dans, J. L., and Griggs, J. A.: A new 1 km digital elevation model of the Antarctic derived from combined satellite radar and laser data - Part 1: Data and methods, The Cryosphere, 3, 101-111, doi:10.5194/tc-3-101-2009, 2009.

Bindschadler, R., Vornberger, P., Fleming, A., Fox, A., Mullins, J., Binnie, D., Paulsen, S., Granneman, B., and Gorodetzky, D.: The Landsat Image Mosaic of Antarctica, Remote Sens. Environ., 112, 4214-4226, doi:10.1016/j.rse.2008.07.006, 2008.

Bromwich, D. H.: Snowfall in High Southern Latitudes, Rev. Geophys., 26, 149-168, 1988.

Budd, W. and Jacka, T.: A review of ice rheology for ice sheet modelling, Cold Reg. Sci. Technol., 16, 107-144, doi:10.1016/0165232X(89)90014-1, 1989.

Carson, C. J., McLaren, S., Roberts, J. L., Boger, S. D., and Blankenship, D. D.: Hot rocks in a cold place: high subglacial heat flow in East Antarctica, J. Geol. Soc., 171, 9-12, doi:10.1144/jgs2013-030, 2014.

Cuffey, K. and Paterson, W.: The Physics of Glaciers, Elsevier, 4th Edn., Burlington, Massachusetts, 2010.

Curran, M. A. J., Ommen, T. D. V., and Morgan, V.: Seasonal characteristics of the major ions in the high-accumulation Dome Summit South ice core, Law Dome, Antarctica, Ann. Glaciol., 27, 385-390, 1998.

Durand, G., Gagliardini, O., Thorsteinsson, T., Svensson, A., Kipfstuhl, S., and Dahl-Jensen, D.: Ice microstructure and fabric: an up-to-date approach for measuring textures, J. Glaciol., 52, 619630, doi:10.3189/172756506781828377, 2006.

Durand, G., Gillet-Chaulet, F., Svensson, A., Gagliardini, O., Kipfstuhl, S., Meyssonnier, J., Parrenin, F., Duval, P., and Dahl-Jensen, D.: Change in ice rheology during climate variations - implications for ice flow modelling and dating of the EPICA Dome C core, Clim. Past, 3, 155-167, doi:10.5194/cp-3-155-2007, 2007.

Duval, P., Ashby, M., and Anderman, I.: Rate-controlling processes in the creep of polycrystalline ice, J. Phys. Chem., 87, 40664074, 1983.

Etheridge, D.: Scientific plan for deep ice drilling on Law Dome, ANARE Research Notes, Kingston, Australia, 1990.
Faria, S. H., Weikusat, I., and Azuma, N.: The microstructure of polar ice. Part I: Highlights from ice core research, J. Struct. Geol., 61, 2-20, doi:10.1016/j.jsg.2013.09.010, 2014a.

Faria, S. H., Weikusat, I., and Azuma, N.: The microstructure of polar ice. Part II: State of the art, J. Struct. Geol., 61, 21-49, doi:10.1016/j.jsg.2013.11.003, 2014b.

Feltham, P.: Grain growth in metals, Acta Metall., 5, 97-105, 1957.

Gagliardini, O., Durand, G., and Wang, Y.: Grain area as a statistical weight for polycrystal constituents, J. Glaciol., 50, 87-95, doi:10.3189/172756504781830349, 2004.

Gao, X. and Jacka, T.: The approach to similar tertiary creep rates for Antarctic core ice and laboratory prepared ice, J. Phys., 48, 289-296, 1987.

Gillet-Chaulet, F., Gagliardini, O., Meyssonnier, J., Montagnat, M., and Castelnau, O.: A user-friendly anisotropic flow law for ice-sheet modelling, J. Glaciol., 51, 3-14, doi:10.3189/172756505781829584, 2005.

Gow, A.: On the rates of growth of grains and crystals in south polar firn, J. Glaciol., 53, 241-252, 1969.

Gow, A. and Meese, D.: Physical properties, crystalline textures and $c$-axis fabrics of the Siple Dome (Antarctica) ice core, J. Glaciol., 183, 573-584, doi:10.3189/002214307784409252, 2007a.

Gow, A. and Meese, D.: The distribution and timing of tephra deposition at Siple Dome, Antarctica: possible climatic and rheologic implications, J. Glaciol., 53, 585-596, 2007b.

Gow, A. and Williamson, T.: Rheological implications of the internal structure and crystal fabrics of the West Antarctic ice sheet as revealed by deep ice core drilling at Byrd station, Geol. Soc. Am. Bull., 87, 1665-1677, 1976.

Gregory, J., White, N., Church, J., Bierkens, M., Box, J., van den Broeke, M., Cogley, J., Fettweis, X., Hanna, E., Huybrechts, P., Konikow, L., Leclercq, P., Marzeion, B., Oerlemans, J., Tamisiea, M., Wada, Y., Wake, L., and van de Wal, R.: Twentieth-century global-mean sea-level rise: is the whole greater than the sum of the parts?, J. Climate, 26, 4476-4499, doi:10.1175/JCLI-D-1200319.1, 2013.

Gundestrup, N. S., Johnsen, S. J., and Reeh, N.: ISTUK: A deep ice core drill system, in: Proceedings of the Second International Workshop/Symposium on Ice Drilling Technology, edited by: Holdsworth, G., Kuivinen, K. C., and Rand, J. H., CRREL Special Report 84-34, 7-19, 1984.

Hamley, T., Morgan, V., Thwaites, R., and Gao, X.: An ice-core drilling site at Law Dome summit, Wilkes Land, Antarctica, Tech. Rep. 37, ANARE Research Notes, 1986.

Jacka, T.: Laboratory studies on relationships between ice crystal size and flow rate, Cold Reg. Sci. Technol., 10, 31-42, 1984.

Jones, S. and Chew, H.: Effect of sample and grain size on the compressive strength of ice, Ann. Glaciol., 129-132, 1983.

Krumbein, W. C.: Thin-section mechanical analysis of indurated sediments, J. Geol., 43, 482-496, 1935.

Langway Jr., C.: Ice fabrics and the universal stage, Tech. Rep. 62, US Army Snow Ice and Permafrost Research Establishment, 1958.

$\mathrm{Li}, \mathrm{J} .:$ Interrelation between the flow properties and crystal structure of snow and ice, $\mathrm{PhD}$ thesis, School of Earth Sciences, University of Melbourne, 1995.

Li, J., Jacka, T., and Morgan, V.: Crystal-size and microparticle record in the ice core from Dome Summit South, Law Dome, East Antarctica, Ann. Glaciol., 27, 343-348, 1998. 
Li, J., Jacka, T., and Budd, W.: Strong single-maximum crystal fabrics developed in ice undergoing shear with unconstrained normal deformation, Ann. Glaciol., 30, 88-92, 2000.

Lile, R.: The effect of anisotropy on the creep of polycrystalline ice, J. Glaciol., 21, 475-483, 1978.

Montagnat, M., Azuma, N., Dahl-Jensen, D., Eichler, J., Fujita, S., Gillet-Chaulet, F., Kipfstuhl, S., Samyn, D., Svensson, A., and Weikusat, I.: Fabric along the NEEM ice core, Greenland, and its comparison with GRIP and NGRIP ice cores, The Cryosphere, 8 , 1129-1138, doi:10.5194/tc-8-1129-2014, 2014a.

Montagnat, M., Castelnau, O., Bons, P., Faria, S., Gagliardini, O., Gillet-Chaulet, F., Grennerat, F., Griera, A., Lebensohn, R., Moulinec, H., Roessiger, J., and Suquet, P.: Multiscale modeling of ice deformation behavior, J. Struct. Geol., 61, 78-108, doi:10.1016/j.jsg.2013.05.002, 2014b.

Morgan, V., Davis, E., and Wehrle, E.: A Rigsby stage with remote computer compatible output, Cold Reg. Sci. Technol., 10, 89-92, 1984.

Morgan, V., Wookey, C., Li, J., van Ommen, T., Skinner, W., and Fitzpatrick, M.: Site information and initial results from deep ice drilling on Law Dome, Antarctica, J. Glaciol., 43, 3-10, 1997.

Morgan, V., van Ommen, T., Elcheikh, A., and Li, J.: Variations in shear deformation rate with depth at Dome Summit South, Law Dome, East Antarctica, Ann. Glaciol., 135-139, 1998.

$\mathrm{Ng}, \mathrm{F}$. and Jacka, T.: A model of crystal-size evolution in polar ice masses, J. Glaciol., 60, 463-477, doi:10.3189/2014JoG13J173, 2014.

Pfitzner, M. L.: The Wilkes Ice Cap Project, 1966, Series A (4) Glaciology 127, ANARE Scientific Reports, Melbourne, Australia, 1980.

Pickering, F. B.: The basis of quantitative metallography, Metals and Metallurgy Trust for the Institute of Metallurgical Technicians, London, 1976.

Pimienta, P., Duval, P., and Lipenkov, V. Y.: Mechanical behaviour of anisotropic polar ice, in: The Physical Basis of Ice Sheet Modelling, 57-65, IAHS Publ. 170, 1987.

Placidi, L., Greve, R., Seddik, H., and Faria, S.: Continuummechanical, Anisotropic Flow model, for polar ice masses, based on an anisotropic Flow Enhancement factor, Continuum Mech. Thermodyn., 22, 221-237, doi:10.1007/s00161-0090126-0, 2010.

Plummer, C. T., Curran, M. A. J., van Ommen, T D., Rasmussen, S. O., Moy, A. D., Vance, T. R., Clausen, H. B., Vinther, B. M., and Mayewski, P. A.: An independently dated 2000-yr volcanic record from Law Dome, East Antarctica, including a new perspective on the dating of the 1450s CE eruption of Kuwae, Vanuatu, Clim. Past, 8, 1929-1940, doi:10.5194/cp-8-1929-2012, 2012.

Roberts, J., Plummer, C., Vance, T., van Ommen, T., Moy, A., Poynter, S., Treverrow, A., Curran, M., and George, S.: A 2000year annual record of snow accumulation rates for Law Dome, East Antarctica, Clim. Past, 11, 697-707, doi:10.5194/cp-11697-2015, 2015.

Roberts, J. L., Warner, R. C., Young, D., Wright, A., van Ommen, T. D., Blankenship, D. D., Siegert, M., Young, N. W., Tabacco, I. E., Forieri, A., Passerini, A., Zirizzotti, A., and Frezzotti, M.: Refined broad-scale sub-glacial morphology of Aurora Subglacial Basin, East Antarctica derived by an ice-dynamics-based inter- polation scheme, The Cryosphere, 5, 551-560, doi:10.5194/tc-5551-2011, 2011.

Russell-Head, D. and Budd, W.: Ice-sheet flow properties derived from bore-hole shear measurements combined with ice-core studies, J. Glaciol., 24, 117-130, 1979.

Schulson, E. and Duval, P.: Creep and Fracture of Ice, Cambridge University Press, 2009.

Seddik, H., Greve, R., Zwinger, T., and Placidi, L.: A full Stokes ice flow model for the vicinity of Dome Fuji, Antarctica, with induced anisotropy and fabric evolution, The Cryosphere, 5, 495508, doi:10.5194/tc-5-495-2011, 2011.

Stephenson, P.: Some considerations of snow metamorphism in the Antarctic Ice Sheet in the light of crystal studies, in: The Physics of Snow and Ice, Proceedings of the International Conference on Low Temperature Science, 1966, edited by: Ôra, H., 725740, Institute of Low Temperature Science, Hokkaido University, Sapporo, Japan, 1967.

Svendsen, B. and Hutter, K.: A continuum approach for modelling induced anisotropy in glaciers and ice sheets, Ann. Glaciol., 262269, 1996.

Thorsteinsson, T.: Fabric development with nearest-neighbour interaction and dynamic recrystallization, J. Geophys. Res.-Sol. Ea., 107, ECV 3-1-ECV 3-13, doi:10.1029/2001JB000244, 2002.

Tison, J.-L., Thorsteinsson, T., Lorrain, R., and Kipfstuhl, J.: Origin and development of textures and fabrics in basal ice as Summit, Central Greenland, Earth Planet. Sc. Lett., 125, 421-437, doi:10.1016/0012-821X(94)90230-5, 1994.

Treverrow, A., Budd, W., Jacka, T., and Warner, R.: The tertiary creep of polycrystalline ice: experimental evidence for stressdependent levels of strain-rate enhancement, J. Glaciol., 58, 301314, doi:10.3189/2012JoG11J149, 2012.

Treverrow, A., Warner, R., Budd, W., Jacka, T., and Roberts, J. L.: Modelled stress distributions at the Dome Summit South borehole, Law Dome, East Antarctica: a comparison of anisotropic ice flow relations, J. Glaciol., 61, 987-1004, doi:10.3189/2015JoG14J198, 2015.

van der Veen, C. and Whillans, I.: Development of fabric in ice, Cold Reg. Sci. Technol., 22, 171-195, doi:10.1016/0165232X(94)90027-2, 1994.

van Ommen, T. and Morgan, V.: Snowfall increase in coastal East Antarctica linked with southwest Western Australian drought, Nat. Geosci., 3, 267-272, 2010.

van Ommen, T., Morgan, V., Jacka, T., Woon, S., and Elcheikh, A.: Near surface temperatures in the Dome Summit South (Law Dome, East Antarctica) borehole, Ann. Glaciol., 29, 141-144, doi:10.3189/172756499781821382, 1999.

van Ommen, T. D., Morgan, V., and Curran, M. A. J.: Deglacial and Holocene changes in accumulation at Law Dome, East Antarctica, Ann. Glaciol., 39, 359-365, doi:10.3189/172756404781814221, 2004.

Vance, T. R., van Ommen, T. D., Curran, M. A. J., Plummer, C. T., and Moy, A. D.: A Millennial Proxy Record of ENSO and Eastern Australian Rainfall from the Law Dome Ice Core, East Antarctica, J. Climate, 26, 710-725, doi:10.1175/JCLI-D12-00003.1, 2013.

Vance, T. R., Roberts, J. L., Plummer, C. T., Kiem, A. S., and van Ommen, T. D.: Interdecadal Pacific variability and eastern Aus- 
tralian mega-droughts over the last millenium, Geophys. Res. Lett., 42, 129-137, doi:10.1002/2014GL062447, 2015.

Vaughan, D., Comiso, J., Allison, I., Carrasco, J., Kaser, G., Kwok, R., Mote, P., Murray, T., Paul, F., Ren, J., Rignot, E., Solomina, O., Steffen, K., and Zhang, T.: Climate Change 2013: The Physical Science Basis. Contribution of Working Group I to the Fifth Assessment Report of the Intergovernmental Panel on Climate Change, chap. 2013, Observations: Cryosphere, Cambridge University Press, Cambridge, United Kingdom and New York, NY, USA, 2013.

Wang, W., Li, J., and Zwally, H.: Dynamic inland propagation of thinning due to ice loss at the margins of the Greenland ice sheet, J. Glaciol., 58, 734-640, 2012.

Wilen, L., Diprinzio, C., Alley, R., and Azuma, N.: Development, principles, and applications of automated ice fabric analyzers, Microsc. Res. Techniq., 62, 2-18, 2003.

Willis, J. and Church, J.: Regional sea-level projection, Science, 336, 550-551, doi:10.1126/science.1220366, 2012.
Wilson, C. and Peternell, M.: Evaluating ice fabrics using fabric analyser techniques in Sørsdal Glacier, East Antarctica, J. Glaciol., 57, 881-894, 2011.

Wilson, C., Russell-Head, D., Kunze, K., and Viola, G.: The analysis of quartz c-axis fabrics using a modified optical microscope, J. Microscopy, 227, 30-41, 2007.

Woodcock, N.: Specification of fabric shapes using an eigenvalue method, Geol. Soc. Am. Bull., 88, 1231-1236, doi:10.1130/0016-7606(1977)88<1231:SOFSUA >2.0.CO;2, 1977.

Yun, W. and Azuma, N.: A new automatic ice-fabric analyzer which uses image-analysis techniques, Ann. Glaciol., 155-162, 1999.

Zwinger, T., Schäfer, M., Martín, C., and Moore, J. C.: Influence of anisotropy on velocity and age distribution at Scharffenbergbotnen blue ice area, The Cryosphere, 8, 607-621, doi:10.5194/tc8-607-2014, 2014. 